\title{
Direitos humanos, refugiados e migrantes: literatura infantil e acolhimento
}

- Derechos humanos, refugiados y migrantes: literatura infantil y Acogimiento

- Human rights, refugees and migrants: children's literature and hosting

\author{
lara Tatiana Bonin \\ Darlize Teixeira de Mello² \\ Liége Freitas Barbosa ${ }^{3}$ \\ Rosa Maria Hessel Silveira ${ }^{4}$
}

Resumo: $\mathrm{O}$ artigo objetiva explorar a fecundidade da literatura infantil para a garantia de um atendimento pleno dos direitos humanos envolvidos em situações de refúgio e migração. Para o desenvolvimento do estudo, foram organizados dois eixos principais: no primeiro, analisamos algumas ações e projetos no âmbito nacional e internacional que visam ao acolhimento das crianças refugiadas ou migrantes através da literatura; no segundo, analisa-

1 Doutora em Educação Professora do Programa de Pós-Graduação em Educação da Universidade Luterana do Brasil. Pesquisadora Produtividade em Pesquisa do CNPq. itbonin@gmail.com

2 Doutora em Educação pela Universidade Federal do Rio Grande do Sila (UFRGS). Professora do Programa em Pós-Graduação em Educação e do Curso de Pedagogia da ULBRA/ Canoas. Associada ao NECCSO/UFRGS. Pesquisadora vinculada ao CNPq. darlizemello@terra.com.br

3 Doutora em Educação pela UFRGS. Mestre em Educação pela ULBRA. Graduada em Comunicação Social. Integrante do NECCSO/UFRGS. liegebarbosa@gmail.com

4 Licenciada e Mestra em Letras, doutora em Educação pela UFRGS. Professora titular aposentada da Faculdade de Educação da UFRGS. Professora colaboradora convidada do Programa de Pós-graduação em Educação da UFRGS. rosamhs@gmail.com 
mos sete obras literárias recentes que abordam as temáticas das migrações e do exílio articuladas de alguma forma com a temática dos direitos humanos. O estudo buscou inspiração em pesquisadores, como Chambers (2007); Colomer (2012); Colomer; Fittipaldi, 2012; Petit (2012; 2013; 2018) que vêm afirmando a potencialidade das narrativas literárias para favorecer situações de acolhimento. Informações relativas a refugiados/migrantes foram buscadas em informes do ACNUR. No estudo, evidenciamos como as narrativas literárias oferecem a possibilidade de imaginar outros mundos e operar uma abertura para a diferença, que inclua o respeito aos direitos à vida, à integridade física, à segurança e à liberdade.

Palavras-chave: Direitos humanos. Migração. Refugiados. Literatura infantil.

Resumen: El artículo tiene como objetivo explorar la fecundidad de la literatura infantil para la garantía de un atendimiento pleno de los derechos humanos involucrados en situaciones de refugio y migración. Para el desarrollo del estudio, fueron organizados dos ejes principales: en el primero, analizamos algunas acciones y proyectos en el ámbito internacional que visan al acogimiento de los niños refugiados o migrantes a través de la literatura; en el segundo, analizamos siete obras literarias recientes que abordan las temáticas de las migraciones y del exilio articuladas de alguna forma con la temática de los derechos humanos. El estudio buscó inspiración en investigadores como Chambers (2007); Colomer (2012); Colomer, Fittipaldi, 2012; Petit $(2012 ; 2013 ; 2018)$ que vienen afirmando la potencialidad de las narrativas literarias para favorecer situaciones de acogimiento. Informaciones relativas a refugiadosimigrantes fueron buscadas en informes de la ACNUR. En el estudio, evidenciamos cómo las narrativas literarias ofrecen la posibilidad de imaginar otros mundos y operar una apertura para la diferencia, que incluya el respeto a los derechos a la vida, a la integridad física, a la seguridad y a la libertad.

Palabras-clave: Derechos humanos. Migración. Refugiados. Literatura infantil.

Abstract: This paper aims to explore the productivity of child's literature as a means to ensure full compliance with human rights in situations of refuge or migration. Two main axes were organized for the development of the study: the first consists of the analysis of projects and actions at the national and international level that aim to welcome refugee or migrant children through literature; the second, seven recent literary works that address the matters of migration and exile articulated with human rights are analysed. This study was inspired by scholars as Chambers (2007); Colomer (2012); Colomer; Fittipaldi, (2012); Petit $(2012 ; 2013 ; 2018)$ as they affirm the potentiality of literary narratives to aid in 
situations of hosting. Information related to refugees and migrants were obtained from UNHCR reports. The study evidences how literary narratives offer the possibility to imagine other worlds and to operate an opening to difference that includes the respect for the rights to life, physical integrity, safety and freedom.

Keywords: human rights. migration. refugees. children's literature.

\section{Palavras iniciais}

É lançando mão de palavras da estudiosa de literatura infanto-juvenil Teresa Colomer (2012, p. 19) que iniciamos o presente artigo. Afirma a autora: "La visión de la literatura como vehículo de compreensión cultural del próprio mundo y de las culturas ajenas ha sido siempre un valor muy presente en la literatura infantil y juvenil'. Se este mote nos inspira, é preciso relembrar, por outro lado, o quanto a presença das 'culturas alheias' esteve, até poucos anos, permeada por olhares colonialistas, racistas, xenófobos e preconceituosos, que matizavam os produtos culturais (livros, filmes, revistas, HQs, canções etc.). Basta mencionar a presença contemporânea de embates constantes entre um revisionismo histórico e uma posição conservadora; defende-se ora o banimento de obras clássicas com um viés hoje condenado, ora a manutenção de sua circulação, desde que sejam feitas ressalvas prévias ao leitor, ora sua adaptação, com supressão e modificações das passagens hoje não mais aceitas.

Mas certo é que a literatura sempre se interessou por outros mundos, outros espaços, outros costumes, outros sujeitos, ficcionalizados em doses e estratégias variadas, mas sempre de forma a oferecer aos leitores outras vidas para serem vividas. Mesmo sendo uma arte que ganha concretude no tempo - da leitura ou da audição de histórias, a literatura está estreitamente ligada ao espaço, como argumenta Petit (2012), ao cunhar um novo epíteto: "La literatura, parte integrante del arte de habitar". A autora aponta, entre outras, três dimensões em que a literatura se conecta ao espaço, afirmando (p.266): "Para que el espacio sea representable y habitable, para que podamos inscribirnos en él, tiene que contarnos historias, poseer todo um espesor simbólico, imaginario, legendário". Espaços sem histórias - familiares, comunitárias, escolares, midiáticas, literárias - seriam apenas parte de um mundo indiferenciado. Por outro lado - e esta dimensão da literatura é bem mais explorada - a leitura de obras literárias permite a construção de um mundo habitável e a possibilidade de nos deslocarmos para dentro dele. Para além de uma reflexão puramente teórica, Petit a conecta com sua experiência da escuta de memórias de leitura, observando: 
Cuando empezé a escuchar a personas que me contaban sus recuerdos de lectura, y entre ellas a muchos hijos de migrantes, me sorprendió la frecuencia com que asociaban estos recuerdos com metáforas espaciales y, de manera más precisa, con un espacio que literalmente les había dado un lugar (p. 268).

Por fim, a ensaísta registra que os elementos do objeto livro - no caso do códex - com seus conteúdos, textos e ilustrações (e acrescentaríamos o projeto gráfico) se conjugam para fazer da leitura uma experiência espacial; professores e mediadores de leitura conhecem bem o folhear e outras ações de exploração do objeto livro que as crianças geralmente empreendem, quando se deparam com novas obras.

Estas reflexões iniciais sobre a íntima relação entre a espacialidade e a literatura, sobre a potência desta para oferecer novas experiências culturais ao leitor, assim como para desencadear a construção de um espaço próprio para ele, em situações de significativo desenraizamento e deslocamento, nos levam ao foco central deste artigo. Nele abordaremos relações entre a literatura infantil e os direitos humanos, centrando-nos principalmente nos direitos que dizem respeito a situações de refúgio e estendendo o âmbito da discussão aos direitos que estão envolvidos em situações de migração.

Nosso objetivo é justamente explorar a fecundidade da literatura infantil - quando concretizada em obras que fujam viés pedagógico e moralista e apostem na abertura de horizontes aos leitores, para a garantia de um atendimento pleno dos direitos humanos envolvidos em situações de refúgio e migração.

Para organizar o presente texto, após esta introdução, traremos um breve cenário sobre Direitos Humanos em sua conexão com a questão dos refugiados e migrantes por questões de deslocamento forçado. Em seguida, aprofundamos duas vertentes da articulação entre literatura infantil e migração. Na primeira, focalizaremos o acolhimento de crianças migrantes através da exploração de livros literários; para tanto, apresentamos e discutimos alguns dados e situações trazidas em bibliografia referente a três contextos e projetos diversos alinhados a esta dimensão. Na segunda vertente, abordaremos a presença da temática da migração e dos refugiados em sete livros infantis de publicação recente, apontando eixos de análise dos mesmos, dentro do horizonte de sensibilização das crianças (em geral) para a questão dos refugiados e migrações através da literatura. Finalmente, apresentam-se considerações finais.

\section{Breve cenário sobre direitos humanos, refugiados e migrantes}

Todo ser humano que seja vítima de perseguição tem o direito de buscar e receber proteção internacional em outro país - é o que afirma o artigo 14 da Declaração Universal dos Direitos Humanos. A agenda política de elaboração de tal declaração, ainda na década de 40, denotava a preocupação com a situação dos refugiados e o dever de protegê-los no cenário pós Segunda 
Guerra Mundial. Passados mais de 70 anos da construção desse documento marco, a reflexão sobre a defesa dos direitos fundamentais e da dignidade da pessoa humana quando seu país de origem não foi capaz de garanti-los, permanece atual e relevante na contemporaneidade.

De antemão, é necessária uma distinção entre os termos "refugiados"e "migrantes", que não são sinônimos e costumam ser confundidos, "o que acarreta problemas para ambas as populações" (ACNUR, 2015). Os refugiados, de acordo com a Agência da ONU para refugiados (ACNUR) ${ }^{5}$, "são pessoas que escaparam de conflitos armados ou perseguições. Com frequência, sua situação é tão perigosa e intolerável que devem cruzar fronteiras internacionais para buscar segurança nos países mais próximos". Já os migrantes são as pessoas que "escolhem se deslocar não por causa de uma ameaça direta de perseguição ou morte, mas [...] para melhorar sua vida em busca de trabalho ou educação, por reunião familiar ou por outras razões" (ACNUR, 2015).

Conforme o ACNUR, até o fim de 2019, 79,5 milhões de pessoas em todo o mundo já haviam sido forçadas a deixar suas casas. Até o mesmo período, o

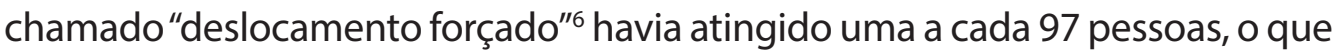
corresponde a mais de $1 \%$ da população mundial. O levantamento mais recente divulgado pelo ACNUR, em junho de 2020, informa que $85 \%$ dos refugiados estão localizados em países em desenvolvimento - o que inclui o Brasil, país que acolhe milhares de refugiados e solicitantes de refúgio em seu território.

Até 2020 havia cerca de 43 mil pessoas vivendo no Brasil na condição reconhecida de refugiadas, sendo que $38 \mathrm{mil}$ ( $88 \%$ delas) são venezuelanas, de acordo com o Comitê Nacional para os Refugiados (CONARE). Este número representa mais de sete vezes o registrado em dezembro de 2019, quando havia cerca de 6 mil pessoas em situação de refúgio no país. Tal aumento significativo no número de refugiados estaria relacionado com o fluxo de deslocamento e com os pedidos de acolhimento feitos pelos venezuelanos, sendo que os filhos desses refugiados também foram reconhecidos (CÁRITAS RJ, 2021). O ano de 2019 foi o que recebeu o maior número de solicitações de refúgio no Brasil, com 82.520 pedidos sendo $66,1 \%$ feitos por venezuelanos,

5 Considerado uma das principais agências humanitárias do mundo, tem como objetivo "a proteção de refugiados e das populações deslocadas por guerras, conflitos e perseguições, buscando soluções duradouras para seus problemas". Dentre outras ações, a agência contabiliza e monitora o número de refugiados, deslocados internos, retornados, solicitantes de refúgio e pessoas apátridas. Fonte: ACNUR (2018; 2021).

6 São múltiplas as causas que levam ao deslocamento forçado, não só situações extremas como guerras ou perseguições políticas. Pessoas também se deslocam para aliviar dificuldades significativas causadas por desastres naturais, pela fome ou extrema pobreza, por exemplo (ACNUR, 2016). 


\section{0,1\% por haitianos ${ }^{7}$ e $4,8 \%$ por cubanos (CONARE ${ }^{8}, 2020$ ).}

Ser reconhecido como refugiado confere a essas pessoas o direito à documentação relativa à sua condição migratória, o acesso ao mercado de trabalho e aos serviços públicos de saúde e educação. No que diz respeito ao Brasil, algumas iniciativas de proteção complementar foram tomadas para atender fluxos migratórios específicos como, por exemplo, no caso de haitianos e venezuelanos. O Ministério dos Direitos Humanos destaca como mecanismos a Lei de Refúgio brasileira (Lei no 9.474, de 22 de julho de 1997) e, recentemente, a entrada em vigor da nova Lei de Migração brasileira (Lei ${ }^{\circ}$ 13.445, de 24 de maio de 2017), que visa consolidar "a perspectiva de direitos humanos no âmbito da política migratória nacional posicionando o país na vanguarda do tratamento da temática [...]" (MDH, 2018).

Atualmente, estima-se que haja entre 30 e 34 milhões de crianças deslocadas pelo mundo - um número efetivamente impressionante. Dados do ACNUR dão conta de que $40 \%$ das pessoas deslocadas no mundo são crianças. Segundo Martuscelli (2017), os menores de 18 anos - conforme determinado pelo artigo $1^{\circ}$ da Convenção das Nações Unidas sobre os direitos da Criança (1989) - "são atores dentro dos fluxos migratórios internacionais seja acompanhando seus familiares ou sozinhos tanto de maneira forçada como voluntária" (p. 78-79). Para discutir a ideia de crianças migrantes, Martuscelli usa a definição de Juffer (2016) como referência, que as entende como sujeitos precários que necessitam da assistência dos adultos, mas que, ao mesmo tempo, são também capazes de manifestar suas experiências e, em determinadas condições, tomar decisões a partir de suas expressões (p. 96).

A preocupação com o bem estar desse grande contingente de crianças refugiadas e migrantes em países que não os de origem, com língua e costumes diversos, quando não em situações de perigo e vulnerabilidade, certamente está na origem de projetos que visam ao uso da literatura infantil em seu acolhimento assim como na produção de obras infantis sobre a temática. Mesmo cientes dos diferentes significados de "migrantes" e "refugiados", mas considerando a semelhança das dificuldades e situações a eles relacionadas que envolvem diferentes direitos humanos, não realizaremos no presente texto nenhuma distinção especifica. Assim, para tratarmos tanto dos projetos de acoIhimento (na seção seguinte) quanto das obras literárias infantis sobre o tema (mais adiante), adotaremos uma dimensão ampliada que engloba as popula-

7 Em relação à leva de haitianos e senegaleses que chegou ao Sul do Brasil desde 2013 e que ganhou visto humanitário do governo brasileiro, estes são considerados imigrantes. Eles não se enquadram nas leis internacionais para refugiados, pois - mesmo buscando escapar de condições precárias de suas nações, da pobreza e desemprego - ainda assim podem retornar aos seus países quando quiserem (SUL 21, 2018).

8 Relatório “Refúgio em números” - 5a edição. Disponível em: https://url.gratis/1nP5g. Acesso em: 11 jan. 2021. 
ções de "refugiados e migrantes" - justamente para darmos conta da multiplicidade de ações acolhedoras e de abordagens realizadas na literatura infantil.

\section{Acolhimento das crianças migrantes pela literatura}

A emergência de ações e projetos que se alinham à dimensão do acoIhimento das crianças refugiadas/migrantes através da literatura frequentemente se conecta a instituições ou grupos já com tradição de pesquisa e trabalho no campo da literatura infantil, assim como a países ou espaços onde questões de migração e diversidade cultural se agudizam. Para desenvolvermos a seção, contextualizaremos três estudos (envolvendo intervenções e pesquisas) deste âmbito, articulando-os, eventualmente, a práticas e concepções que circulam atualmente sobre a relação criança/livros literários.

Assim, mencionamos inicialmente um trabalho que começou a ser gestado em 2006, no Grupo de Investigación de literatura infantil y juvenil y educación literaria de la Universitat Autònoma de Barcelona (GRETEL), do qual temos notícia através de vários artigos da obra La literatura que acoge: inmigración y lectura de los albumes (COLOMER; FITTIPALDI, 2012). Colomer (2012, p. 12) retoma duas convicções inspiradoras do trabalho: a de que a literatura seria um "lugar privilegiado" para a aprendizagem da língua de acolhida dos migrantes (e relembremos a importância da diferença linguística como uma das barreiras mais relevantes nos casos de migrações) e a convicção "de que la literatura facilita la reflexión sobre la realidad pluricultural".

Considerando-se a própria condição bilíngue da Catalunha (assim como da América Latina, de países africanos da região do Magreb e da Europa oriental), o trabalho de investigação/ação do GRETEL partiu de um diagnóstico sobre a escassa presença da literatura na acolhida dos alunos migrantes. Tendo como lugar privilegiado o espaço escolar, o trabalho teve como horizonte"la renovación de la enseñanza de lenguas en contextos plurilíngues, explorando el uso literário y algunas formas didácticas de proceder en esta nueva situación socioeducativa" (COLOMER, 2012, p. 13). Entre as decisões norteadoras do trabalho com os alunos migrantes, estava a escolha dos chamados livros ilustrados; isto é, obras com grande componente visual, cujo manuseio tanto minimizava a barreira da língua quanto possibilitava rica interação das crianças em torno dos livros. É preciso considerar a variedade da denominação de tais obras - nas quais a ilustração não é apenas decorativa, mas protagoniza também a narrativa - em diversos países: são chamadas de picturebooks (em inglês), libros-álbun (em espanhol) e livros ilustrados, na tradução brasileira mais corrente.

O relato do trabalho inicialmente realizado - que posteriormente se ramificou e se integrou a uma pesquisa internacional - aponta que foram traba- 
Ihados tanto livros com a temática da migração, quanto obras em que situações migratórias estavam presentes apenas de forma indireta, assim como aquelas que se abriam à compreensão da interculturalidade e da diferença de modo mais geral (ora personificada em personagens humanos, ora metaforizada em animais ou outros seres). Abrangendo alunos migrantes de diferentes escolas de Barcelona, com um amplo espectro etário (6 a 16 anos) e de origem (19 países), falantes de mais de 10 línguas diversas, os apontamentos trazidos sobre o projeto evidenciam um protocolo do qual faziam parte (entre outras ações) uma primeira leitura conjunta do livro, um debate coletivo sobre a interpretação textual em que se incentivava, sob inspiração de Aidan Chambers (2007),

\section{[...] el debate aberto sobre cualquier tema que suscitara el interés, no sólo de la narración [...] sino también sobre los elementos compositivos del libro, así como sobre la propia implicación vital de los lectores: sus identidades, países, elementos culturales propios, conocimientos pré- vios relacionados com la discusión, etc. (COLOMER, 2012, p. 17)}

Já a Red Internacional de Investigación de Literatura Infantil, outra iniciativa a ser destacada, é uma organização acadêmica internacional criada para apoiar e promover pesquisas no campo da literatura infantil, presente em mais de 40 países. Entre seus objetivos está a promoção de pesquisas acadêmicas em literatura infantil e juvenil, leitura e áreas afins, através da cooperação entre pesquisadores de diferentes países e campos de aprendizagem. Neste estudo destacaremos a pesquisa Literatura infantil en contextos críticos de desplazamiento: La creación de "espacios seguros" para niños y jóvenes a través de prácticas basadas en el cuento y el arte, coordenada por Evelyn Arizpe, da Universidad de Glasgow, Escócia.

Em 2018, o projeto citado acima realizou uma série de ações, que resultaram em jornadas para refletir sobre o uso da literatura infantil e das artes tendo em vista ajudar a negociar os desafios atuais decorrentes de contextos de fluxos migratórios, violência e pobreza, começando pelo México e Egito, e com a ideia de estender a rede aos países vizinhos. Entre as jornadas realizadas, os integrantes da Rede participaram do

Encuentro Internacional de Mediadores y Promotores de Lectura en contextos Migrantes, no México, coordenado por membros do Programa Nacional Salas de Lectura do México. Neste espaço, os mediadores compartilharam resultados do projeto de intervenção cultural, realizado com a população de migrantes, denominado Leer con migrantes. Destas jornadas resultou o livro Para leer en contextos adversos y otros espacios emergentes, organizado pela Secretaria de Cultura, cidade do México, em 2018, sendo alguns artigos deste material a fonte referência para o presente trabalho.

Já no contexto brasileiro, destacamos a pesquisa Ser criança estrangeira: rodas de conversa com crianças imigrantes, coordenada por Leni Dornelles, da 
Universidade Federal do Rio Grande do Sul (UFRGS), realizada entre 2017-2019. Nela, se procurou retratar o modo como as crianças migrantes de 3 e 4 anos se manifestavam e eram visibilizadas no cotidiano de uma escola de educação infantil da periferia de Porto Alegre/RS, a partir do objetivo central de analisar como se produzem e são produzidas tais crianças em meio a um cotidiano escolar tão diverso do de sua terra natal. Um artigo a que tivemos acesso traz um recorte de resultados desta pesquisa (Dornelles et al., no prelo), especificamente focalizando o trabalho com uma obra de literatura infantil em roda de conversa, e ele servirá de fonte investigativa para este estudo.

Passamos, agora a destacar dois aspectos destas pesquisas que contemplam tal aproximação: a centralidade das conversas sobre leitura e a relevância da escolha dos livros para tal trabalho.

A realização de conversas conjuntas sobre livros trabalhados constitui uma ferramenta poderosa para a articulação entre pertencimento e conexões com os outros ${ }^{9}$. Todos os projetos mencionados utilizaram os espaços de conversa conjunta como forma de criar momentos nos quais migrantes e/ou refugiados e mediadores de leitura pudessem compartilhar suas experiências passadas e presentes, provocadas pelas obras. Assim, num contexto de diálogo, as questões abertas das conversas literárias podem auxiliar na construção de significados mais profundos. Deste modo, o estímulo à leitura e o planejamento de ações pedagógicas propositivas e potencializadoras foram pautas dos estudos e pesquisas em questão. Os mediadores de leitura/pesquisadores do projeto Leer con migrantes, da Red Internacional de Investigación de Literatura infantil, por exemplo, atuando em contextos frágeis de deslocamentos, têm se reunido com grupos de sujeitos que tiveram que deixar seu lugar de origem e têm trazido a leitura como ferramenta para circulação de culturas, pela riqueza de línguas, culturas ou tradições distintas, expressa pelas narrativas (ARIZPE, 2018). Também a pesquisa nas escolas catalãs, como já mencionado, incorporava o debate coletivo sobre as obras, abrindo-se a quaisquer interesses que as crianças ou adolescentes manifestassem a partir dos livros.

Já no projeto brasileiro referido (Dornelles et al., no prelo), desenvolvido em escola de educação infantil, a brincadeira, a música e a dança, assim como a literatura infantil, foram elementos mobilizadores do encontro com o outro, potencializando conversas e permitindo a visibilização dos sentidos

9 A ênfase em conversas compartilhadas sobre leituras literárias tem se beneficiado das reflexões de Chambers (2007), inspiradoras de projetos em diferentes países, incluindo o Brasil. Neste sentido, pode-se citar o projeto "Percursos e representações da infância em livros para crianças - um estudo de obras e de leituras" (NECCSO, apoio $\mathrm{CNPq}$ ), que permitiu constatar a produtividade da conversa literária sobre obras que abordam temas 'difíceis', polêmicos, como pode ser exemplificado no artigo: "Conversas literárias com crianças sobre diferenças e temas polêmicos” (SILVEIRA, BONIN, KIRCHOF. No prelo) 
que as crianças atribuíam a práticas de sua existência. No recorte a que tivemos acesso, são discutidas rodas de conversa a partir da obra O cabelo de Lelê, de Valéria Bonfim, cujo tema é a busca da protagonista - uma menina negra - pelo conhecimento de suas origens. O uso de ilustrações originais, em um projeto gráfico renovado, e de um texto econômico, mas instigante, destaca a identidade negra, a partir da valorização da imagem física (beleza) e intelectual (protagonismo). As crianças migrantes do projeto - no caso, haitianas e senegalesas, negras - "buscavam imagens de suas pertenças raciais no livro para interpretarem seu mundo e construírem positivas representações simbólicas de si e do outro" (Dornelles et al., p. 8). Assim, as rodas de conversa colocaram "em ação uma negritude positivada, uma pedagogia antirracista a partir da qual elas pareciam encontrar condições (e elementos visuais e narrativos) de falar de si mesmas, de encontrar seu modo de ser e valorizar suas tradições culturais" (Dornelles et al. p. 8).

Nestas conversas sobre leitura, o mediador da leitura desempenha um papel fundamental, considerando que ele "facilita el acercamiento al libro, guía la selección de textos, estimula la lectura y el diálogo de forma sensible e invita a compartir emociones y formas de expresión distintas"; neste sentido, "puede ser una inspiración para seguir adelante" (ARIZPE, 2018, p. 27).

Um segundo aspecto a ser destacado nestes estudos é a relevância da escolha dos livros a serem utilizados com as crianças/adolescentes migrantes. Em primeiro lugar, enfatiza-se a riqueza do trabalho com os chamados livros ilustrados - em que a combinação estética de palavras e dos elementos visuais (ilustrações/projeto gráfico) produz significados em diferentes níveis, com poder para abrir espaços para diferentes leitores. Os livros ilustrados contemporâneos tendem a ser atraentes, incitando a curiosidade e provocando o ímpeto de criar uma narrativa coerente e completa, através da articulação entre palavra e imagem, que proporciona um equilíbrio no impacto das palavras quando se trata de temas fortes e emocionais. Para além da escolha de livros ilustrados, deve-se atentar a uma constatação de Margallo (2012, p. 145), que diz respeito à oferta editorial (espanhola, no caso) para alunos migrantes. Após registrar a existência de edições multilíngues com mostras de folclore das culturas dos migrantes, e de livros com relatos sobre eventos cotidianos dos países de origem, a autora adverte para o risco de tais obras - ou de seu uso exclusivo - em manterem simbolicamente os migrantes em seus lugares de origem, enclausurando-os em sua "estrangeiridade". Por outro lado, Petit (2013), ao analisar depoimentos de sujeitos com pouco acesso à cultura escrita, observa como jovens realizaram "deslocamentos", reais ou metafóricos, a partir das leituras. Para a autora, a leitura "pode sacudir a representação que [os jovens] têm de si mesmos, sua maneira de pensar, suas relações com a família, com o grupo 
de pertencimento, com a cultura de origem, e evita às vezes que sejam reféns de uma representação estereotipada dessa cultura" (p. 114).

Neste sentido, percebemos que os estudos e pesquisas com a literatura, em especial com o tema da migração, mostram a ativação de vários processos cognitivos e afetivos nos leitores, pois apelam para a história de personagens marginalizados, de tal forma que podem representar uma esperança para 0 leitor com uma história semelhante (ARIZPE, 2018). Corroborando este aspecto, Petit (2018, p. 19) aponta que:

Leer [...] en contextos adversos y otros espacios emergentes [puede servir para] dar una profundidad simbólica, imaginaria y legendaria a lo que nos rodea, una profundidad desde la cual soñar, derivar, asociar. proyectar en lo cotidiano un poco de belleza, de fábulas, de historias. Sirve para armonizar, en el sentido musical del término, o para reconectar con el mundo que nos rodea al abrir otra dimensión.

Por fim, salientamos a importância de que as obras com as quais se trabalha em tais projetos sejam consideradas como objetos estéticos e lúdicos, e não textos para aprendizado formal ou para transmitir "mensagens" intencionais. Tampouco a leitura e as atividades devem ser confundidas com terapia ou biblioterapia. É impossível reparar o mundo, mas é possível abrir algumas portas e janelas para crianças e jovens se expressarem e serem ouvidos, terem um momento de humanidade (ARIZPE, 2018).

No entanto, como sabemos, na prática, o acolhimento da diversidade ainda se coloca como um desafio a ser conquistado; afinal, vários são os exemplos de exclusão, racismo e repulsa ao diferente em nossa sociedade. Contudo, essas pesquisas sobre leitura infanto-juvenil e as conversas literárias, nos diferentes espaços, parecem-nos possibilitar pensar em como "el arte y la literatura, en todas sus formas [...] son apoyos importantes para revivir la capacidad de ensueño, de creatividad, de activación de símbolos, de construcción de significado" (PETIT, 2018, p. 20), de tal forma que estimulem nos leitores a constituição de estratégias de resistência e de identificação, em tempos que se podem configurar como híbridos, reativos e significativos.

\section{Exílio e migração em sete obras de literatura infantil selecionadas}

Para desenvolvermos esta análise, selecionamos sete títulos publicados no Brasil a partir de 2012, cuja temática central é a da migração/exílio e cuja complexidade permite situá-los como passíveis de serem explorados com alunos de anos iniciais e, eventualmente, crianças da educação infantil. São livros nos quais se exploram recursos variados para a composição de narrativas que trazem, para o leitor-criança, tramas de vidas inscritas em violência ou em condições que levaram à decisão de migrar.

Migrando é um livro apenas de imagens, criado pela ilustradora argenti- 
na, radicada na Itália, Mariana Chiesa Mateos ${ }^{10}$. O projeto editorial apresenta dois percursos de leitura em sentidos opostos, com duas capas que sinalizam direções diferentes de leitura, sendo que as duas narrativas visuais se encontram exatamente na metade do livro. Na contracapa a narrativa é assim caracterizada:

Migrando tem duas capas, dois pontos de partida, mas é indiferente por onde se começa a viagem. Neste livro, aves e pessoas cruzam os céus. Fazem as malas, abrem as asas e lançam-se à aventura... Dedicada aos que deixaram a sua terra para re-existirem noutro lugar, esta história sem palavras e de imagens poéticas, mostra como a palavra migrante pode ser sinónimo de sofrimento e fragilidade, mas também de coragem e futuro.

Já a obra Um outro país para Azzi11 consiste em uma narrativa que utiliza a distribuição espacial e gráfica de histórias em quadrinhos, com autoria da inglesa Sarah Garland, e foi publicada, em nosso país, pela Editora Pulo do Gato em 2012. A narrativa - que praticamente não se vale dos recursos das HQs contemporâneas, como balões de fala e pensamento - é feita por um narrador onisciente, que apresenta o contexto inicial, marcado pela guerra e pela necessidade de fuga da família nuclear da personagem criança. Na contracapa antecipa-se o conflito: "Azzi e seus pais correm perigo e precisam fugir às pressas, deixando para trás sua casa, seus parentes, seus amigos, seus trabalhos e sua cultura" (GARLAND, 2012, s/p). Mas, para a protagonista, ter de deixar para trás a avó é o que configura a maior razão de sofrimento e saudade.

Também da Editora Pulo do Gato, selecionamos os títulos Eloísa e os bichos e Para onde vamos, ambos de autoria do colombiano Jairo Buitrago e ilustrações do cubano Rafael Yockteng, publicados no Brasil em 2013 e 2016, respectivamente. Os textos são escritos em primeira pessoa, favorecendo que o leitor imagine e recrie situações que possivelmente não vivencie, ligadas à condição da personagem migrante. Em ambas as histórias, a protagonista/ narradora é uma menina: na primeira, o tema central é a adaptação da criança a um contexto que, inicialmente, é estranho e assustador para ela (daí, a alusão aos "bichos" e as ilustrações de animais assustadores); aos poucos, o contexto se torna familiar a partir da inserção da menina na escola e da possibilidade de recriação de um espaço de vida com qualidade. Já na segunda obra, o foco recai sobre o deslocamento feito clandestinamente e partilhado com outros migrantes, para atravessar fronteiras nacionais. Os perigos da travessia são construídos ora de forma denotativa, como a presença de guardas armados nas ilustrações, ora metaforicamente, com a representação de elementos como a figura de um coiote animal (alusão ao homônimo humano) e

10 A produção, apoiada pela Amnistia Internacional, Portugal, para divulgação, circula por diversos países, tendo sido publicada no Brasil pela Editora 34, em 2015.

11 Aprovado pela Anistia Internacional 2013; e, ainda, prêmio Little Rebels Children's Book, em 2013. 
de coelhos correndo em liberdade, ao final.

A viagem, escrita e ilustrada pela italiana Francesca Sanna, foi editada em 2016, no Brasil, pela Vergara \& Riba Editoras. Na contracapa da obra, um paratexto interpela o leitor: "Como deixar tudo para trás e viajar quilômetros rumo a um lugar estranho? Essa é a jornada de milhões de refugiados em redor do mundo". A narrativa - feita em primeira pessoa, com textos verbais curtos e predomínio de imagens - expõe, na perspectiva de uma criança, o arriscado e solitário caminho da família (mãe e dois filhos pequenos) para escapar de um contexto de guerra e para buscar outro lugar para viver.

Migrar ${ }^{12}$, criação dos mexicanos José Manuel Mateo, texto, Javier Martínez Pedro, ilustração, foi publicado no Brasil pela Editora Pallas em 2013. O livro usa uma técnica de contar histórias do povo mexicano Xalitla, que envolve a saturação do espaço da página com imagens que recriam cenas do cotidiano. Impresso em preto e branco, a obra tem um formato de gaita, amarrada com uma fita, que se desdobra verticalmente, formando um único painel com textos numa coluna à esquerda. As ilustrações são densas, descritivas e convidam a uma leitura demorada das cenas que dialogam com ações descritas no texto, em primeira pessoa, por um narrador-criança. A obra constrói um contexto anterior à migração (a vida do narrador-criança em pequena cidade mexicana), seguido da jornada deste e de sua família, cruzando clandestinamente a fronteira estadunidense em busca do pai. O desfecho está marcado pela condição de clandestinidade e pela inserção precoce em ocupações laborais fatigantes.

A menina que abraça o vento: a história de uma refugiada congolesa foi escrito pela brasileira Fernanda Paraguassu e ilustrado pela artista plástica, também brasileira, Suryara Bernardi. Publicada em 2017 pela Editora Vooinho, traz textos verbais curtos e ilustrações amplas, criadas com técnica de colagem e sobreposições de traços de aquarela. A narrativa, em terceira pessoa, tem como protagonista a pequena menina Mersene, "que teve que se separar de parte da família para fugir do triste conflito vivido na República Democrática do Congo", conforme a sinopse da obra. O título alude à brincadeira criada pela protagonista para amenizar a saudade de seu pai, que permaneceu no país de origem, enquanto ela e sua mãe migraram para o Brasil.

Ao selecionar estas obras, pretendemos observar como - em suas narrativas e através de variados recursos literários - a migração e o exílio são constituídos como questões atinentes aos direitos humanos. Antes, porém, parece oportuno indicar como se explicitam, nos paratextos ${ }^{13}$ destes livros, os

12 Vencedor da categoria New Horizons, na Feira do Livro de Bolonha, Itália, em 2012.

13 Entendemos paratexto como o conjunto de fragmentos verbais amplos ou reduzidos que acompanham o texto propriamente dito da obra. Assim, um prefácio, a biografia do autor e ilustrador, a sinopse, a dedicatória, uma nota do autor ou da editora, um posfácio, os comentários na margem, os glossários são exemplos de paratextos (MAIN- 
vínculos entre suas narrativas ficcionais e os contextos migratórios imaginados, vividos ou conhecidos pelos autores.

No título Migrando, por exemplo, o texto de apresentação da autora afirma que ela pretendeu criar "uma obra poética aberta a múltiplas interpretações e que, assim como o próprio fenômeno da migração, propõe ao leitor a experiência de vários pontos de vista ao mesmo tempo" (MATEOS, 2015, s/p). Já em $A$ viagem, uma nota final da autora registra: "A viagem é a história de muitas viagens. Tudo começou com duas meninas que conheci em um centro de refugiados na Itália. Neste encontro, notei que havia algo muito poderoso nas histórias delas. Então, fui coletando mais depoimentos sobre migração" (SANNA, 2016, s/p). Também na obra Um outro país para Azzi encontramos argumento semelhante, na biografia da autora. Sua inspiração para a escrita teria emergido do contato com famílias de refugiados; o estudo das memórias de pessoas que precisaram fugir indicou aspectos comuns como solidão, saudade, dificuldades de adaptação e de vínculos de trabalho, frequentemente menos prestigiados ou não condizentes com o nível de qualificação do migrante.

A brasileira Fernanda Paraguassu também vincula a narrativa de Mersene ( $A$ menina que abraça o vento: a história de uma refugiada congolesa) às histórias reais de meninas congolesas refugiadas no Rio de Janeiro, em sua "tocante capacidade de superar a dor e a saudade". Já os paratextos da obra Migrar contextualizam a narrativa e, ainda, abordam processos migratórios do México para os Estados Unidos, nos quais crianças também fazem o arriscado percurso de travessia clandestina da fronteira, muitas vezes desacompanhadas. As razões para a migração são elencadas - a esperança de encontrar paz, trabalho, tranquilidade; a intenção de fugir da pobreza, dos maus-tratos, da violência generalizada - assim como os riscos da travessia, desde os perigos do caminho e a ameaça de captura por guardas das fronteiras, até a possibilidade de exploração, roubo e abuso por organizações criminosas que atuam nestes contextos fronteiriços. Denunciam-se, assim, outras violações de direitos das pessoas migrantes, por já terem sido submetidas a condições indignas, inseguras, insustentáveis que as transformam em pessoas indefesas e invisíveis. Por fim, alerta-se para o fato de que muitos destes migrantes clandestinos nunca chegam ao destino pretendido - desaparecem, vítimas do tráfico humano, ou morrem no caminho.

Nos paratextos, ao expressarem as motivações para a escrita das obras, refere-se ao anseio para que haja reconhecimento, tolerância e respeito aos direitos (humanos, sociais, culturais) das pessoas que migram. Assim, na contracapa de Eloísa e os bichos afirma-se que a obra "oferece um terno e renovado

GUENEAU, 2001, p. 81). 
olhar para questões sociais como a migração, a diversidade e a tolerância". Na contracapa de Um outro país para Azzi, indica-se que o livro"permite que leitores de qualquer idade possam imaginar o que é ser uma criança refugiada em processo de adaptação" (GARLAND, 2012, s/p). Também em Para onde vamos, explicita-se num paratexto "o desejo de que as crianças brasileiras que lerem possam saber um pouco mais sobre a vida de outras crianças que, como elas, gostam de brincar e de contar, mas que precisam muitas vezes sair de suas casas até encontrarem um novo lugar para morar em paz". De forma contundente, um paratexto do livro Migrar afirma o anseio de tornar conhecida uma situação de violência que se desenrola silenciosamente:"com esse papel, com suas palavras e desenhos, contamos a história dos que conseguem chegar, para não esquecer que há mulheres, homens e sabe-se lá quantas meninas e meninos que desaparecem ou morrem no caminho".

A seguir, focalizaremos três elementos das obras que, a nosso ver, constituem os eixos principais para a análise de aspectos concernentes aos direitos humanos: o contexto inicial e a motivação que deflagram o ato de migrar; as ações vinculadas ao percurso migratório e, por fim, os processos de adaptação e os desfechos das histórias.

\section{A caracterização dos contextos iniciais e as motivações para 0 ato de migrar}

$\mathrm{Na}$ análise dos livros selecionados, observamos que o ato de migrar é recriado ficcionalmente a partir de uma abrupta ruptura com um território com o qual os personagens têm ligações de pertencimento. Algumas histórias partem de uma situação inicial de tranquilidade, seguida de conflitos que culminam no ato de migrar. Assim, sob a perspectiva de um narrador-criança, a obra A viagem inicia como segue:

\footnotetext{
Eu vivia com a minha família em uma cidade perto do mar. Durante o verão, costumávamos ir à praia. Mas nunca mais fomos lá, pois, no ano passado, nossas vidas mudaram para sempre... A guerra começou. Todos os dias, coisas ruins aconteciam à nossa volta e, em pouco tempo, não havia mais nada além do caos. Até que a guerra levou o meu pai. Desde então, tudo se tornou mais sombrio, e minha mãe ficou ainda mais preocupada (SANNA, 2016, s/p).
}

Os espaços retratados nas ilustrações iniciais, coloridas e alegres, vão sendo inundados por espessa mancha preta, metaforizando o desenrolar da guerra, que, por fim, cobre toda a extensão das páginas a partir do ponto em que se anuncia a morte do pai da personagem-narradora e a família decide migrar.

De modo semelhante, na obra Um outro país para Azzi, a narrativa apresenta um cenário inicial tenso e conflitivo que emoldura e dá sentido ao ato de 
migrar: "Havia um país em guerra, e é lá que começa essa história. A cada dia a guerra se aproximava mais e mais da casa de Azzi, embora sua vida permanecesse a mesma" (GARLAND, 2012, s/p). As imagens mostram destroços de bombardeios em uma paisagem urbana, seguidas de cenas em que a protagonista brinca enquanto a avó e a mãe realizam tarefas domésticas (plantar, tecer, costurar) e o pai, médico, atende a doentes. Para além dos muros de seu jardim, a personagem vê soldados marchando, helicópteros, tanques e outros símbolos de guerra. Neste ponto da narrativa, o personagem pai recebe uma ligação: "Papai ouviu o que Ihe diziam e seu rosto empalideceu com o choque. Ele falou depressa:'Entrem no carro! Temos que partir agora mesmo'"' (GARLAND, 2012, s/p).

A obra Migrar descreve, também a partir de um narrador criança, uma situação inicial serena e sem conflitos

Eu brincava de correr entre galos e porcos. Os animais andavam soltos, porque na roça não havia currais ou cercas entre as casas [...] Eu gostava de pular de um sulco a outro, para brincar e para não pisar nas plantas... Também gostava de me esconder atrás das palmeiras (MATEO, 2013, s/p).

Gradualmente, contudo, explicita-se uma situação problema que, diferentemente das obras anteriores, não é de guerra: "o terreno era grande, mas não pertencia ao meu pai"; "Mas as coisas mudaram de repente! Os vizinhos pararam de plantar. Primeiro o Seu Augusto se foi. Em um ano voltou e levou os filhos homens. O mesmo fizeram os demais adultos"; "Sobraram apenas mulheres e algumas crianças"; "Minha mãe quis plantar no terreno, mas o dono não deixou. Procurou emprego, mas pagavam sempre muito pouquinho" (MATEO, 2013, s/p). Os acontecimentos encadeiam-se de modo a dar sentido à decisão da personagem mãe de migrar, também, com as crianças.

Em A menina que abraça o vento: a história de uma refugiada congolesa, o ponto de partida da personagem é localizado geograficamente e descreve-se de maneira singela a motivação para a situação de guerra: "A menina nasceu em um país que fica longe daqui. Do outro lado do oceano, no continente Africano. Lá na República Democrática do Congo, um país muito grande e cheio de riquezas. Tem ouro, tem diamantes, tem pedrinhas pequenas que todo mundo quer [...] Tudo é tão valioso por lá que muita gente briga por causa dessas riquezas. Brigam tanto que as pessoas que moram ali precisam fugir para não se machucar" (PARAGUASSU, 2017). Em Para onde vamos - apesar da ausência de menção clara às razões para a migração - um paratexto traz razões por que pai e filha teriam deixado para trás o mundo em que viviam: "talvez o pai não consiga arrumar um trabalho ou não tenha condições para manter sua filha em seu próprio país; ou porque o lugar em que viviam foi destruído pela violência, pela guerra ou por conflitos" (BUITRAGO, 2016, s/p).

Nas obras acima citadas (e algumas, dentre as analisadas, não abordam as razões de partida), vimos que o abandono do país de origem se dá 
em virtude de guerras ou conflitos, da ação violenta de grupos opressores ou, ainda, do desemprego e da precariedade de condições de vida. São, portanto, marcados certos contextos de violações de direitos humanos e, em especial, dos direitos das crianças. A situação de risco para a segurança familiar parece ser a razão comum para que os personagens empreendam a viagem em busca de outras condições de vida, em lugares distantes.

\section{As ações, acontecimentos e perigos da viagem}

As narrativas das obras analisadas presentificam os perigos enfrentados em jornadas cruelmente reais, em que famílias nucleares seguem sozinhas ou em grupos, em condições precárias e na clandestinidade. Ainda assim, os acontecimentos são recriados com delicadeza por imagens ou metáforas que buscam estabelecer similaridade com um olhar de criança. Há ações cuja menção é comum a mais de uma obra e, nelas, se recriam perigos da travessia (às escondidas) feita pelos personagens.

Nos ombros do pai e com uma pequena mochila, a personagem de Para onde Vamos inicia a viagem, contando animais, plantas, nuvens que vê pelo caminho. Nesta brincadeira, que se estende do início ao fim da jornada, se produz um espaço de brincar em contraponto à dureza da travessia. Na primeira parada, o pai apresenta-a a um coiote - nomeado no texto verbal e ilustrado com o personagem animal -, que segue presente em todas as cenas da travessia. Num paratexto da obra, explicita-se o significado de "coiote" no contexto de imigrações ilegais; mas, na narrativa, apenas a figura do animal permanece como uma chave a ser interpretada. Na narrativa visual, as ilustrações dão conta de partes da travessia - os personagens viajam numa balsa que cruza a fronteira, acampam junto a outros migrantes; viajam clandestinamente sobre vagões de trem, em carrocerias de veículos, até chegar ao simbólico muro que separa México e Estados Unidos. A narrativa tem final aberto, com a imagem de dois coelhos brancos, companheiros de viagem no final do percurso, um presente de outra criança com quem a protagonista fez amizade, agora correndo livres numa paisagem inóspita.

Em A viagem, a partida é marcada pela figura da mãe mostrando um livro com imagens de um país distante e diferente, indicativo do planejamento de um destino. No percurso, a família leva inicialmente grande quantidade de malas e viaja "por muitos dias", passando de um veículo a outro. O narrador informa: "quanto mais nos distanciávamos... mais coisas iam ficando para trás"; as imagens mostram a família com sucessiva diminuição de pertences e em veículos cada vez mais precários, até a chegada à fronteira. O desafio de escapar de guardas armados e de atravessar o muro dialoga com as histórias dos migrantes 
contemporâneos. A viagem segue pelo mar, em um bote frágil e superlotado e, depois, em um trem. O desfecho da narrativa é aberto, com a liberdade conquistada representada metaforicamente por imagens de aves migratórias. Ao final, o narrador-criança enuncia o desejo: “Espero, um dia, como esses pássaros, que consigamos encontrar um novo lar. Um lar onde possamos ficar seguros e recomeçar a nossa história" (SANNA, 2016, s/p), o que pode produzir identificação do leitor com as expectativas de segurança e qualidade de vida da protagonista.

Em Migrar, texto verbal e imagens vão construindo o percurso de viagem - de caminhão, sobre vagões de um trem, o esconderijo em buracos na terra, a perseguição por guardas acompanhados de cães farejadores, por exemplo. $O$ sentido de perigo da travessia clandestina é intensificado com a passagem: "perseguiam as pessoas e as colocavam em uns caminhões amarelos [...] dessa vez tive medo de que nos agarrassem, porque se te pegam, você desaparece..." (MATEO, 2013, s/p).

Também em Um outro país para Azzi, a fuga da família ocorre repentinamente e à noite eles abandonam a casa, despedindo-se da avó, que decide permanecer. Uma longa e arriscada travessia é descrita, já que a menina não tinha documentos para viajar legalmente. Iniciado por via terrestre, o percurso segue pelo mar, em um bote e junto a outros migrantes. A fome, a sede e o cansaço são sublinhados no texto verbal e intensificados em imagens, nas expressões exaustas dos personagens. A nova casa, bem mais modesta do que aquela deixada no país de origem, enuncia a precarização da vida.

Em A menina que abraça o vento: a história de uma refugiada congolesa, a informação de que a personagem menina "saiu correndo da casa [...] com os irmãos e a mãe, fugindo para bem longe" é complementada com imagens de objetos espalhados em um cômodo da casa e de uma porta ainda aberta. Informa-se, ademais, que a família correu por ruas cheias de gente, viajou por dias em um barco e, ainda, de avião, até chegar ao Brasil, marcadores de longa distância percorrida até o país de destino.

Já em Migrando - livro de imagens com duas histórias que se encontram - os elementos visuais aludem a vários processos migratórios, utilizando elementos referenciais e elementos metafóricos - principalmente pássaros migratórios, ora representados de forma mais realista, ora como aves, conduzindo às costas personagens humanos ou como híbridos aves-pessoas. As dificuldades das migrações estão estampadas em barcos apinhados de pessoas (referência às travessias do Mediterrâneo), em personagens negras escalando cercas de arames farpados, ou correndo por bosques com guardas armados no encalço de migrantes ilegais. Tais imagens se misturam com cenas de dolorosas despedidas humanas, assim como a reflexões das próprias personagens, mesclando menções a migrações passadas (dos europeus à América, por exemplo) e referências às penosas diásporas africanas atuais. 
Observa-se, por fim, que em muitas destas obras a descrição verbal dos percursos e dos desconfortos do caminho é, sobretudo, sensorial, envolvendo imagens vistas (e descritas), sons de animais da floresta, sensação de frio, sede, fome, cheiros e gostos de alimentos deixados na cultura de origem e de outros, do lugar de passagem ou de moradia. A experiência vivida pelas personagens no espaço e no tempo corporifica-se em sensações sugeridas ao leitor, talvez como estratégia para construir proximidade e identificação a partir de suas próprias experiências sensoriais.

\section{Como as narrativas compõem e apresentam os proces- sos de adaptação}

Os processos de adaptação a um novo contexto social, linguístico e cultural no país de chegada são eventualmente tematizados nas histórias narradas. Nesta seção, analisaremos a representação de ações posteriores à chegada dos personagens ao destino final, naquelas obras em que tais elementos ocupam parte significativa da narrativa.

Assim, os processos de adaptação recriados na ficção podem envolver expressões iniciais de medo, como se vê em Eloísa e os Bichos, obra cuja temática é justamente a inserção dos migrantes em um novo espaço. A afirmação "Eu não sou daqui" abre a narrativa, e as ilustrações mostram a pequena menina, com seu pai, circulando por uma cidade povoada por insetos e outros animais que simbolizam os "outros". A menina se mostra assustada quando seu pai a deixa, de mãos dadas com a professora "inseto", na porta da escola, enquanto vai procurar trabaIho. Lá, conforme o texto, ela se sentia "um bicho estranho" e seu desconforto é marcado também pela referência ao tempo psicológico: "os recreios eram muito longos... tão demorados quanto ficar esperando papai chegar na hora da saída". À medida, em que a personagem vai fazendo amigos, o tempo passa a correr agilmente - "Os dias passavam mais depressa. Pouco a pouco, começamos a nos sentir em casa" (BUITRAGO, 2013, s/p). Um efeito interessante empregado, ao final da narrativa, é a inversão da forma de figurativização dos personagens - agora é a protagonista que aparece como uma espécie de inseto, enquanto os demais personagens da escola aparecem como humanos.

A escola é também espaço central no acolhimento e adaptação da protagonista de Um outro país para Azzi. É na escola que, apesar do temor inicial de não entender o professor, não ser entendida e não fazer amigos, ela aprende a falar a língua do novo país e passa a conviver com outras crianças. Contudo, na escola ela conta com o auxílio de uma tradutora que fala a sua língua materna e, no recreio, conta com o acolhimento de outras meninas que a inserem nas brincadeiras. A saudade do que ficou para trás expressa-se, em particular, na falta da 
avó, por quem a menina chora à noite. Há, por outra via, marcas de precarização da vida dos migrantes, em elementos como a casa com apenas um cômodo, pobremente mobiliada, a escassez de alimentos sobre a mesa e a necessidade de cozinhar grãos de feijão guardados para o plantio, ou em dificuldades encontradas pelo pai para obter trabalho, denotadas no texto verbal e nas imagens.

Mersene, protagonista criança da obra $A$ menina que abraça o vento: a história de uma refugiada congolesa, também encontra na escola um espaço de aprendizagem de expressões em língua portuguesa, além de diversão, onde "brinca de faz de conta, canta para a boneca e pula sem parar" (PARAGUASSU, 2017, s/p). A saudade do pai e de sua casa, no país de origem, é fator de entristecimento para a personagem, mas o texto verbal sugere que ela "sabe que não pode voltar agora" e "enquanto espera, Mersene trata de viver que nem as outras crianças daqui. Ela tem a hora pra estudar, hora pra brincar e hora pra dormir. De noite, na cama, Mersene sonha" (PARAGUASSU, 2017, $\mathrm{s} / \mathrm{p})$. A saudade intensa motiva a invenção da brincadeira de abraçar o vento como se ele fosse o personagem pai distante.

Vê-se, assim, como, nas narrativas dos livros analisados, afirmam-se, sutilmente, os direitos de refugiados e exilados - o direito ao acolhimento, o direito de acesso à escola com condições de acessibilidade comunicacional e considerando as diferenças culturais e linguísticas, o direito ao trabalho, à liberdade, entre outros, princípios que, de certo modo, se concretizam em alguns desfechos. Mas a violação de tais princípios também pode ser exemplificada nas narrativas, através situações nas quais avulta o desrespeito aos direitos humanos - os contextos de guerra e violência do país de origem, a exploração sofrida ao longo do caminho, o medo e o desconforto nas travessias clandestinas, a precarização das condições de vida no país de destino. Em particular, destacamos o desfecho da obra Migrar, no qual o personagem passa a morar em casa com muitos outros migrantes, de distintos países, e é prematuramente inserido em atividades laborais - limpando casas. Tais contextos de privação são, entretanto, retratados com positividade frente ao sofrimento e à violência deixados para trás.

Tal como observa Colomer (2012), ao analisar um conjunto de 50 obras literárias publicadas na Espanha entre 2000 e 2010, que tematizam migração e exílio, as dificuldades enfrentadas pelos personagens são, em geral, integradas a uma dimensão maior: a do reconhecimento e da garantia de direitos, aliada a uma busca por desenvolver atitudes positivas de leitores em relação ao acolhimento, à integração e à convivência com migrantes e refugiados. Por outro lado, várias obras então analisadas traziam uma descrição pouco complexa dos processos migratórios, além de exibirem, em alguns casos, um olhar estereotipado sobre os locais de origem dos migrantes. 
Nas sete obras discutidas neste artigo, inscreve-se, de um modo ou de outro, a possibilidade de reconstrução de uma vida regida sob os princípios dos direitos humanos, mesmo quandoessa possibilidade éadiada ou deixada em suspenso nos desfechos, nas situações finais em que os personagens permanecem em trânsito - como em A Viagem e Para onde vamos. Nas histórias narradas nas demais obras analisadas, os personagens concretizam o desejo de encontrar um novo lar, um lugar seguro, um espaço para recomeçar ou para recobrar o curso da vida em segurança.

\section{Considerações finais}

Neste estudo, cujo objetivo foi explorar a potencialidade da literatura infantil - através de obras que fogem à estereotipia, ao pedagogismo, ao moralismo e apostam na abertura de horizontes aos leitores - para a garantia de um atendimento pleno dos direitos humanos envolvidos em situações de refúgio e migração, estabelecemos dois eixos principais. Por um lado, consideramos ações e projetos que visam ao acolhimento de crianças refugiadas ou migrantes através da literatura; por outro lado, analisamos sete obras de literatura infantil para entender como nelas se enlaçam as temáticas da migração/exílio com a dos direitos humanos. No primeiro caso, discorremos sobre três ações que envolvem pesquisa, intervenção e análise de dados gerados em sessões de leitura de obras literárias com crianças e jovens migrantes, projetos estes envolvendo países da Europa, América, incluindo o Brasil. Tais ações e pesquisas fazem parte de um leque mais abrangente de estudos de diferentes países, nas quais a migração e o exílio são tomados como acontecimentos contemporâneos relevantes e desafiadores.

Já a análise das obras de literatura selecionadas possibilitou entender como, por variados recursos literários e estéticos, a migração e o exílio são constituídos como questões atinentes aos direitos humanos. $\mathrm{O}$ tema se enuncia ora em paratextos - que situam e contextualizam a inspiração para as histórias ora na narrativa central, em textos e imagens que constituem enredos ficcionais sobre migrantes ou exilados, inspirados em grande medida na escuta de pessoas em tal condição. Nossa análise se debruçou em especial sobre a forma como as obras apresentam os lugares de origem das personagens, as razões para a decisão de migrar; os percursos migratórios, seus perigos, desconfortos e tensões e, por fim, a forma como trazem e tratam elementos dos processos de adaptação dos personagens (migrantes/refugiados) aos países de destino.

Unimo-nos a outros pesquisadores e pesquisadoras que vêm afirmando a fecundidade das narrativas literárias para favorecer situações de acolhimento, uma vez que estes textos - e outros mais, que trabalhem esteticamente a questão da diferença, da pluralidade cultural e da dimensão humana, enfim - têm o 
potencial de promover certa identificação de leitores migrantes com situações narradas, com as dificuldades e temores enfrentados nos processos de exílio e migração. $E$, de modo ainda mais abrangente, essas narrativas oferecem a possibilidade de imaginar outros mundos, contextos marcados pela violência e pela necessidade de abandonar o que se conhece e aceitar o desafio de estar refugiado ou migrante. Observamos, em especial, que nas sete obras discutidas neste artigo, se inscreve um anseio de reconstrução de uma vida regida sob os princípios dos direitos humanos. Ao ampliar experiências estéticas de leitores que não passaram pelas mesmas situações de migração e refúgio, a literatura pode também promover a disposição para a solidariedade e o acolhimento.

Pensamos, assim, que as obras de literatura infantil podem operar uma abertura para a diferença que não signifique apenas o reconhecimento de que existem muitas línguas, culturas, histórias, memórias, formas de existir e de (re) existir no mundo, mas que inclua o respeito aos direitos à vida, à integridade física, à segurança, à liberdade. Especificamente em relação aos direitos das crianças, a leitura de livros de literatura com personagens crianças migrantes/ refugiadas pode colaborar para que se reconheça que são vitais para elas a proteção contra a violência, negligência ou tratamento displicente, o direito à assistência humanitária adequada e a um ambiente acolhedor, conforme os Artigos 13, 19 e 22 da Convenção sobre os Direitos da Criança da ONU. Talvez, por meio de histórias de viagens nem sempre sonhadas, desejadas, planejadas, se possa promover empatia para com os "outros" (haitianos, senegaleses, venezuelanos e de tantas outras nacionalidades) que migram ou se refugiam em nosso país.

\section{Referências}

ARIZPE, Evelyn. Literatura infantil en contextos críticos de desplazamiento: el Programa "Leer con migrantes". In: Secretaría de Cultura/DGP. Para leer en contextos adversosy otros espacios emergentes. México: Dirección General de Publicaciones, 2018. p. 23-65.

ALTO COMISSARIADO DAS NAÇÕES UNIDAS PARA OS REFUGIADOS (ACNUR). Dados sobre Refúgio. 2020. Disponível em: https://url.gratis/w8Q2n. Acesso em: 7 jan. 2021.

ALTO COMISSARIADO DAS NAÇÕES UNIDAS PARA OS REFUGIADOS (ACNUR). Refugiado ou migrante? O ACNUR incentiva a usar o termo correto. 2015. Disponível em: https://url.gratis/4Juew. Acesso em: 7 jan.2021.

ALTO COMISSARIADO DAS NAÇÕES UNIDAS PARA OS REFUGIADOS (ACNUR). Protegendo refugiados no Brasil e no mundo. 2018. Disponível em: https://url. gratis/jTerM Acesso em: 8 jan. 2021. 
ASSEMBLEIA GERAL DA ONU. (1948). Declaração Universal dos Direitos Humanos (217 [III] A). Paris. Disponível em: https://url.gratis/mXJkJ. Acesso em: 7 jan. 2021.

CÁRITAS-RJ. Programa de Atendimento a Refugiados e Solicitantes de Refúgio (PARES). Números do Refúgio no Brasil. 2020. Disponível em: https:// url.gratis/QQIxO. Acesso em: 9 jan. 2021.

CHAMBERS, Aidan. Dime. Espacios para la lectura. México: Fondo de Cultura Economica, 2007.

COLOMER, Teresa. La literatura que acoge: un proyecto de investigación en las aulas. In: COLOMER, Teresa; FITTIPALDI, Martina (coord.). La literatura que acoge: inmigración ylectura de albumes. Barcelona: Banco del Libro - GRETEL, 2012. p. 1-25.

COMITÊ NACIONAL PARA OS REFUGIADOS (CONARE). Ministério da Justiça e Segurança Pública. Refúgio em números e publicações. 2020. Disponível em: https://url.gratis/G5WUb. Acesso em: 6 jan. 2021.

DORNELLES, Leni Vieira et al. Ser criança imigrante: aprendendo sobre pesquisa com crianças refugiadas no sul do Brasil. [No prelo].

JUFFER, Jane. Can the children speak? Precarious subjects at the US-Mexico border. Feminist Formations, Baltimore, v. 28, n. 1, p. 94-120, 2016.

MAINGUENEAU, Dominique. Análise de textos de comunicação. São Paulo: Cortez, 2001.

MARGALLO, Ana Maria. Que literatura para los recién llegados. In: COLOMER, Teresa; FITTIPALDI, Martina (coord.). La literatura que acoge: inmigración y lectura de albumes. Barcelona: Banco del Libro - GRETEL, 2012, p. 1-25.

MARTUSCELLI, Patrícia Nabuco. Crianças desacompanhadas na América Latina: reflexões iniciais sobre a situação na América Central. Revista Interdisciplinar de Direitos Humanos. Bauru, v. 5, n. 1, p. 77-96, jan./ jun., 2017.

MINISTÉRIO DA MULHER, DA FAMÍLIA E DOS DIREITOS HUMANOS. Os Refugiados e os Direitos Humanos. 2018. Disponível em: https://url.gratis/XXh81. Acesso em: 10 jan.2021

PETIT, Michèle. La literatura, parte integrante del arte de habitar. In: COLOMER, Teresa; FITTIPALDI, Martina (coord.). La literatura que acoge: inmigración y lectura de albumes. Barcelona: Banco del Libro - GRETEL, 2012. p. 263-280. 
PETIT, Michèle. Leituras: do espaço íntimo ao espaço público. Tradução: Olga de Souza. São Paulo: Editora 34, 2013.

PETIT, Michèle. Transfigurar el horror en beleza. In: Secretaría de Cultura/DGP. Para leer en contextos adversos y otros espacios emergentes. México: Dirección General de Publicaciones 2018. p. 15-21.

SUL 21. Refugiados ou imigrantes? Entenda diferenças entre venezuelanos e outros estrangeiros que chegam ao país. Reportagem. 2018. Disponível em: https://url.gratis/6QUDj. Acesso em: 11 jan. 2021.

\section{Livros de literatura infantil citados}

BELÉM, Valéria. O cabelo de Lelê. São Paulo: Companhia Editora Nacional, 2007.

SANNA, Francesca. A Viagem. Tradução de Fabrício Valério. São Paulo, SP: Vergara e Riba, 2016.

BUITRAGO, Jairo. Eloísa e os bichos. Ilustrações de Rafael Yockteng. Tradução de Márcia Leite. São Paulo: Editora Pulo do Gato, 2013.

BUITRAGO, Jairo. Para onde vamos. llustrações de Rafael Yockteng. Tradução de Márcia Leite. São Paulo: Editora Pulo do Gato, 2016.

GARLAND, Sarah. Um outro país para Azzi. Tradução de Érico Assis. São Paulo: Editora Pulo do Gato, 2012.

MATEO, José Manuel. Migrar. llustrações de Javier Martínez Pedro. Tradução de Rafaella Lemos. São Paulo: Editora Pallas, 2013.

MATEOS, Mariana Chiesa. Migrando. Tradução de José Colaço Barreiros. São Paulo: Editora 34, 2015.

PARAGUASSÚ, Fernanda. A menina que abraça o vento: a história de uma refugiada congolesa. Ilustrações de Suryara Bernardi. Curitiba:Vooinho, 2017.

Recebido em: 15 de janeiro de 2021.

Aprovado em: 25 de maio de 2021. 